\section{Climial demartis}

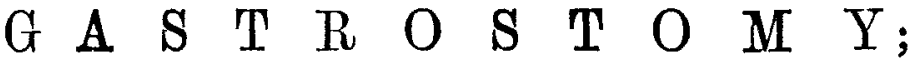 WITH CASES.}

BY THOMAS JONES, F.R.C.S., SURGEON TO THE MANCHESTER ROYAL INFIRMARY.

GaS'RoSTomy, formerly so uniformly unsuccessful, promises to become a palliative measure of decided utility. To Sédillot, of Strasburg, belongs the credit of introducing both the operation and the name. In 1849 he performed gastrostomy on a male patient fifty-two years of age, who was the subject of cancerous stricture of the cesophagus. The stomach was opened at once, and the aperture in it fitted with a tube, which embraced an elastic catheter, introduced for the purpose of conveying nourishment. Unfortunately the attempt proved unsuccessful, as also did a repetiton of it during many succeeding years. The record of the cases operated upon between 1849 and 1876 constitutes an unbroken series of failures. The operation was repeated some twenty-five times, and most of the patients died within the first few days; some of them lived periods varying from four to ten days, and one survived forty days. In 1876, Verneuil, of Paris, obtained the first real success. His patient, a healthy lad, seventeen years of age, some months previously had swallowed a solution of caustic potash. This was followed by intense pain in the throat, with exfoliation of the mucous membrane of the stomach. When the acute symptoms subsided the patient experienced great difficulty in swallowing. The dysphagia increased, and attempts at catheterism of the gullet were frequently made, but without success. The stricture was situated about seven inches below the upper end of the gullet, and so low as to preclude the idea of cesophagostomy ; it was therefore decided to perform gastrostomy. The portion of stomach exposed was carefully stitched to the lips of the wound in the peritoneum and abdominal wall. The viscus was then laid open and a vulcanite tube introduced. The patient made a good recovery, and almost at once was able to take liquid food through the artificial opening. At the time of operation the weight of the patient was $72 \mathrm{lb}$, a month later $75 \mathrm{lb}$, and three months later $92 \mathrm{lb}$. The lad lived seventeen months.

I have referred somewhat at length to this case becanse it forms the commencement of an important era, and constitutes the first of a limited number of successful gastros. tomies. Since 1876 the operation has been frequently repeated. The most elaborate statistics of the results are those published oy Blum. ${ }^{1}$ He tabulates 131 gastrostomies, of these eighty-five died before the twentieth day - that is, in consequence of the operation, and so giving a mortality of nearly 65 per cent. Thirty-eight have survived the operation from several months to two years and more. One other point which these statistical tables bring out is worthy of our attention. By eliminating the gastrostomies for cancerous disease of the cesophagus we have left twenty-five examples in which the operation has been performed for fibrous or non-cancerous strictures. Of these only twelve patients died before the twentieth day, showing a mortality of 48 per cent. I think that if the merits of gastrostomy had no other basis than its success in non-cancerous strictures, it ought to claim our respectful consideration, and it is quite possible that if in cancerous cases we resorted to the operation at an earlier period and before the patient's powers had fallen to a low ebb, the successes would be more numerous. What particularly attracted my attention while perusing reports of gastrostomy cases was the rapid sinking soon after the operation. The little remaining strength has been quite unequal to the task of rallying. Even in these cases by an improvement in the mode of operating the chances of a successful issue are very materially increased. In THE LANCET of January $7 \mathrm{th}$, 1882, I published a successful gastrostomy for non-cancerous stricture of the cesophagus. The patient (a female, now aged twenty-two) is still alive, and is able to work in a cotton mill, while she continues to introduce fluid food through the artificial open-

No. 3180 . ing. Quite lately, through the kindness of my friend Mr. Waller, late house-surgeon to the Blackburn Infirmary, I have been able to obtain an accurate statement of her condition. He writes to say that he has visited Mary $\mathrm{N}-$, and found her in a very satisfactory condition. The general nutrition is good, and saliva and fluids can be swallowed with ease. The gastric aperture is patent, and is kept so by the patient constantly wearing a small plug, which accurately fits the artificial opening. A short time ago there was some slight eczema around the opening, which has no $\mathrm{N}$ disappeared. The patient's weight was found to be $101 \mathrm{lb}$, which is considerably more than when she was last seen at the infirmary. This case must be regarded as one of the most satisfactory gastrostomies. Here was a patient doomed to one of the most distressing deaths-that from inanitionrestored to a condition of comparative comfort; and it is quite possible deglutition may continue to improve, and that eventually dilatation of the stricture may be accomplished.

CASE 2. - Ann W-, aged forty-tive, was admitted under Dr. Dreschfeld's care on June 21st, 1882. She was found to be suffering from stricture (malignant) of the cesophagus. There was no history of syphilis, and no corrosive fluid had been swallowed. Present disease com. menced seven months before admission, with vomiting immediately after taking food. She soon began to lose flesh and to experience shooting pains down the inner side of the left arm. The vomiting was not accompanied by any exertion, but simply consisted of the regurgitation of unaltered food. An cesophageal bougie passed readily a distance of thirteen inches, when its progress was suddenly arrested. While under treatment emaciation steadily advanced, although she was fed by nutrient enemata. On July 3rd the patient was transferred to a surgical ward under my care, with the view of gastrostomy being performed. No difficulty was experienced during the performance of the first part of the operation, which was done on July 4th. The stomach was easily reached by making an incision below the left costal margin, commencing above opposite the anterior extremity of the seventh intercostal space. Care was taken that all oozing had entirely stopped before the peritoneum was incised. The stomach presented at the opening, and its peritoneal and muscular coats were stitched to the margins of the skin incision. The parietal peritoneum was not included. The number of sutures (chromised catgut) employed did not exceed half a dozen, and I feel convinced that the unfortunate termination of the case must to a certain extent be attributed to this cause. For six days afterwards no special symptoms appeared. The temperature continued about the normal, and there was an absence of pain. During this time the patient was exclusively fed on enemata, which consisted of three ounces of beef-tea or milk (peptonised) and four drachms of whisky every two hours. On July 10th the antiseptic dressings were removed, and the wound appeared healthy. The stomach was now opened with a tenotomy knife, a catheter introduced, and a small quantity of warm milk injected. The next day a pint of milk was administered by the artificial aperture, while the nutrient injections were continued. The patient progressed favourably until the 16th, when through an unlucky mishap a pint of cold milk was poured into the stomach. Immediately she became collapsed, and was seized with a rigor afterwards the temperature rose to $102^{\circ}$, delirium, followed by insensibility, supervened, and the patient died in about fifteen hours. A short abstract of the post-mortem examination is appended. The body was well developed, but greatly emaciated. The margins of the gastrostomy incisions were united to the walls of the stomach, except at one part, where no adhesion had taken place. The tissues in the region of the incision were more or less infiltrated with purulent matter, and the underlying peritoneum acutely inflamed. The peritoneum was coated with a thin layer of inflammatory exudation. This was most marked (excluding the vicinity of the wound) in the region of the ovaries, both of which were intensely congested. The cesophagus was normal down to three inches and a half from the cardiac end, where the lumen was almost obliterated by a dense whitish mass of new formation (cancerous), which involved the whole circumference of the tube, and extended downwards about an inch and $a$ half. To all appearance the fatal termination was immediately due to the accidental administration of milk which had not been properly warmed. The post-mortem, however, revealed an amount of peritonitis which in all probability had been going on insidiously for some days, 
although the temperature and general symptoms contraindicated such an assumption. The case clearly shows that great care is absolutely needed in carrying out the aftertreatment. The milk or other fluid food poured into the stomach through an artificial opening should have a tem. perature of not less than $100^{\circ}$

CASE 3.-Sarah A-_, widow, aged fifty, was admitted into the infirmary under Dr. Leech's care in August, 1883. She was an in-patient for a week in March of the present year; was then sent to Cheadle Convalescent Hospital, where she remained six weeks, and appeared to derive considerable benefit. Her symptoms at that time were chiefly those of dyspepsia, with attacks of vomiting every three or four weeks. The vomited matter consisted of a dark brown fluid, which bore some resemblance to coffee grounds. Pain of an aching character, referable to the region of the stomach, accompanied each act of vomiting. No family predisposition to cancer could be discovered, and inquiry into a history of syphilis only gave negative results. Patient had never swallowed any corrosive fluid. The passage of an oesophageal bougie determined the presence of a stricture which was impassable and situated about fifteen inches and $a$ half from the mouth. On August 16th, 1883, she was transferred to the surgical side of the infirmary. At that time she was very haggard, and had an exhausted anæmic appearance. For some days she had been fed on peptonised beef-tea and milk administered by the rectum. The injections were continued, and her weight increased from $90 \mathrm{lb}$. to $95 \mathrm{lb}$. Any fluid food given by the mouth appeared to stop before it reached the stomach, and in a few minutes was regurgitated. On Sept. 20 th the first part of the operation of gastrostomy was performed with antiseptic precautions. No difficulty of any kind was met with, and the stomach was easily drawn forwards and sutured to the skin. In order to accurately approximate the peritoneal and cutaneous surfaces the number of sutures employed was about a dozen. After the operation all food by the mouth was stopped, and the patient fed by enemata of beef jelly and milk (an ounce of each) every two hours. The temperature for the most part maintained a normal course, reaching $99^{\circ}$ on the 22nd. There was freedom from pain or any symptom of peritonitis. Fortunately the enemata were well retained. On the 26th the dressings were removed for the first time; the parts appeared healthy, and adhesions had taken place between the opposed surfaces. I now proceeded to make an opening into the stomach by means of a tenotomy knife. Through the opening a cannula was passed, and about a third of a pint of milk injected. This caused a stomachache, and during the night the patient became collapsed, and complained of pain in the abdomen. The cannula was withdrawn, and all attempts at the introduction of milk postponed until Oct. 4th-i.e., for eight days. Meanwhile the local and general symptoms indicated an attack of circumscribed peritonitis. For a week the temperature continued at or about $100^{\circ}$, and one evening it exceeded $101^{\circ}$. The fever had subsided by Oct. 4th, when a more successful attempt to open the stomach was made. A cannula was again inserted through a puncture produced by the tenotomy knife and six ounces of milk introduced. The cannula was retained in situ until the next day, when sixteen ounces of milk were poured into the stomach without causing any pain or inconvenience. The nutrient enemata were discontinued on Oct. 10th, and four pints of milk were administered daily through the artificial opening. About a month after the date of the first operation she was weighed, and found to be $87 \mathrm{lb}$, which is $9 \mathrm{lb}$. less than her weight immediately before operation. Six weeks later the weight was again taken and an increase of $13 \mathrm{lb}$. recorded. Each time the patient has been seen since her discharge a considerable increase in the weight has been noted. The patient is now in the enjoyment of very good health. The artificial opening occasions no inconvenience, nor does the surrounding integument bear any evidence of regurgitation. She is quite satisfied with the fluid food, and its introduction causes no sensation, except that of heat or cold. The condition of the stricture remains practically the same, and any food which is swallowed is instantly rejected.

CASE 4. Ann B-, aged thirty-nine years, admitted under Dr. Leech's care, on Oct. 12th, 1883. She is emaciated to an extraordinary degree, and, although of ordinary stature, she only weighs four and a half stones. The history of dysphagia extended back a year and ten months, and has been accompanied by symptoms of dyspepsia. At first the sickness recurred at intervals of a fortnight, but lately it has taken place immediately after each meal. She says. she feels the milk pass down a certain distance, where it remains a tew minutes and is then regurgitated. The patient has never swallowed any corrosive fluid, and no history of syphilis or cancer can be elicited. An cesophageal bougie. can be easily passed a distance of twelve inches from the mouth. Its further progress is then suddenly and com. pletely arrested. Three days after admission she was transo ferred to the surgical ward. For some time an attempt, partially successful, to improve her condition was made. $B y$ the aid of nutrient enemata her weight was increased by four pounds. On Nov. 3rd the first part of the operation was. performed. No difficulty was experienced, the stomach. being easily reached and brought forward. During the following week the patient was in an exceedingly low condition, and fears were entertained that it would be quite impossible to preserve life until the stomach opening could safely be made. However, by the careful administration of enemata and the free use of stimulants I succeeded in carry. ing her through a very anxious period. The opera tion was completed on Nov. 10th, and ten ounces of milk were at once introduced through the newly made opening without producing any pain or uneasiness. In a few days the quantity of milk administered by the artificial aperture was increased to five points, so the nutrient injec tions were discontinued. For some time she was much troubled by the regurgitation of a dark, grumous, exceed ingly offensive fluid, which was brought ap whenever she had a fit of coughing. No doubt it came from the cesophagus, which, in all probability, was dilated above the stricture Its gastric origin was excluded by the non-appearance of the milk in the regurgitated fluid when the stomach was opened The quantity of fluid gradually diminished, and finally ceased. Very soon she began to improve in appearance and to put on flesh, and we were able to register an increase of $8 \mathrm{lb}$. in her weight. Since her return home she has been heard of from time to time. At first there was a steady and continuous improvement, and she added considerably to her weight. Unfortunately, however, the amendment has been arrested by an attack of pneumonia, from which she is slowly convalescing.

CASES 5 and 6 terminated fatally about thirty hours after operation. Both were males. One patient, seventy years of age, had suffered dysphagia for thirteen months. From the distance the bougie traversed it was judged that there existed a stricture at the lower extremity of the cesophagus. No difficulty attended the operation. The patient rallied well, and remained free from pain for more than twentyfour hours, when the symptoms suddenly declared the onset of peritonitis. The temperature rapidly rose, and death took place in a few hours. In the other patient, a man forty-seven years of age, the sequence of events was practically the same. Death followed the operation after a similar interval, and was preceded by symptoms of a like nature. As no post-mortem examination was made in either case, the exact state of things must remain a matter of conjecture

It should benoted that the method of operatinginall the foregoing cases was that introduced by Mr. Howse. It constitutes an undoubted improvement over the plan formerly in vogue. By delaying the second stage of the operation for some days we obtain adhesions between the peritoneal covering of the stomach and the margins of the skin incision, so that when the stomach opening is made extravasation of the gastric: contents into the peritoneal cavity is effectually prevented. French surgeons seek the same end by a double row of sutures, the first row between the parietal peritoneum and the serous covering of the stomach, and the second between the skin and the gastric opening. Mr. Howse's plan is preferable, and for several reasons. It not only removes all chances of extravasation into the peritoneal cavity, but it permits the first and most important part of the operation to be conducted with antiseptic precautions. Everyone who haspractised gastrostomy will have been struck with the simplicity of the operation. As a rule, the stomach is found without any trouble being experienced. The late $\mathrm{Mr}_{\text {r }}$ Maunder, however, encountered a serious difficulty which caused him to open the transeverse colon instead of the stomach. To avoid a similar accident Schönborn has suggested that a small indiarubber bag should be fixed to the end of an cesophageal tabe. As soon as the latter reaches the stomach the bag is distended. This brings the anterior wall of the stomach into the wound and the operation is clearly rendered easier. Of course this suggestion presupposes the permeability of the 
stricture, which is rarely the case, and when present would perhaps contra-indicate an operation. An attempt has been made to institute a comparison between cesophagostomy and gastrostomy. It would appear that they are applicable to different cases. Esophagostomy may be appropriately employed in those cases where the obstruction is seated in the apper part of the gullet. Experience, however, teaches that these constitute the smallest class. It has been found that in nearly two-thirds of the cases of cesophageal cancer the disease is so situated as to render cesophagostomy inadmissible.

Some discussion has taken place in regard to the position which the gastric aperture should occupy. Langer, ${ }^{2}$ arguing from physiological data, concludes that the fistula should be established in the cardiac portion, and not, as is frequently done, in the pyloric part of the organ. No doubt surgeons have made the opening in that portion of the viscus which presents, and I think it will be found that this is generally nearer the pyloric than cardiac extremity.

\section{THE UNIVERSALITY OF CHOLERA.}

BY DEPUTY SURG.-GEN. W. T. MOORE, C.I.E.

CholerA may be defined as a disease always present and frequently becoming epidemic, generally characterised by purging and vomiting, usually of a material resembling ricewater, commonly accompanied by cramps, and frequently resulting in suppression of urine and collapse. But the term cholera implies a principle which is repugnant to the disease; the term cholera signifies a flow of bile, but the want of bile is usually one of the most prominent peculiarities of the complaint. It is impossible, therefore, to use the term cholera without pointing out the absurdity of an expression which literally implies, not what it ordinarily is, but what it ordinarily is not. And this should be borne in mind, as tending in some degree to account for the numerous names under which cholera has been described, as a consequence of the numerous phases in which it develops itself. Allen $W^{2} b^{3}$ long since remarked that much of the mystery and obscurity which attaches to cholera results from its having been regarded-since 1832 in Europe and since 1817 in India -as an entirely new and previously unheard-of malady ; and he shows, by quotations from Snohruta, Wangohoo, and other ancient authors, that cholera is as old as India or China. "It is not always the same in its nature or effects. It is allied in its nature to some of the most desolating pestilences, as well as to some of the most common diseases." In its virulent form it begins, as Magendie observed, "in death." On the other hand, as with all other diseases, there may be a most mild and scarcely recognisable form of the malady. Of all writers, Macpherson ${ }^{4}$ has, I think, most elaborately and satisfactorily shown that cholera is one of the most ancient diseases of which distinct descriptions exist, prevailing both in Europe and Asia from the earliest times. In support of the view of cholera having prevailed in early times in Europe, Macpherson refers to Hippocrates and Galen, who described a malady very similar to modern cholera; and he further demonstrates that cholera in one or other of its diverse forms has been described by successive European authors almost from the time of the ancients mentioned to the present date, and especially during the 14th, 15th, 16 th, and 17 th centuries. That cholera has been looked upon as a new disease in Europe since 1832 may be explained by the facts that medical writings of a reliable nature referring to former times were few, and that many of the writings extant, in consequence of the extraordinary variations which occur in the manifestations of the disease itself, do not describe that typical cholera which occurred in 1832 , and which has come to be accepted as the only phase of the malady. Even analogous reasoning would teach that cholera prevailed in Europe and England in former times; for, as Surgeon-Major Waters ${ }^{5}$ points out, considering that cholera is endemic only in countries where fevers of a malarious character are invariably to be found, and that these were common in England till a comparatively recent period-James I, and Cromwell having died of ague,-it

2 Progrès Médical, Nov. 3rd, 1883

3 Pathologrogres Medcal, Nov. 3rd, 1883 .

5 Lecture on Epidemics at the Sassoon Institute, Bombay, 1884. may be inferred that when the latter prevailed in full virulent vigour, the former occurred in epidemic periodicity, as it does in India.

In support of the view of the antiquity of the malady in the East, there is the fact that the early Sanskrit writers were apparently well acquainted with cholera. In the Midan of Snohruta there is a description of a disease termed. "vishuchuka" (meaning purging, vomiting, and fever). which was clearly cholera ; while in other old Hindu medical works we have "jivat antishat," meaning fever and incessant purging. Then there is the significant fact that all the languages of the peninsula of India have a time-honoured name for the disease. Further, it appears to have been well known to the Mahomedan conquerors as "haidsa" or "haiza," and it has been shown that cholera prevailed among the Mahomedans of Delhi in 1325. There is also a record in Todd's "Ragasthan," that temples to "Oola Bebee," the goddess of cholera, were found by the first European visitors in India. Macpherson makes the pertinent observation that as it is certain the Portuguese found cholera in India soon after their arrival in 1500, especially at Goa in 1540, it is only reasonable to believe that it existed in India previously. Mr. Gaskoin translated from the Portuguese a distinct notice of the disease occurring in 1503 , when, as testified by Gasper Corea, 20,000 men belonging to the army of Zamoryn, King of Calicut, died, "sudden-like with pain in the belly." But the first full account given by a European physician was by Garcia D'Orta, of Groa, who, in 1653 , pointed out several varieties of cholera, much as they exist now. The ideas, therefore, which have been held by many, and as stated below, cannot be regarded as tenableviz., that Bontius in 1630 was the first writer on cholera; that cholera is a comparatively recent disease ; and that, as concluded by the Constantinople Cholera Congress of 1854 , some change came into operation about the year 1817, giving rise to the first great Indian cholera epidemic.

Even assuming, as Bryden held, that Bontius in 1630 first described cholera, I have before me references to no less than fifteen distinct notices of the disease from that period to 1784. Dr. Waters, indeed, states there are no less than sixty separate and independent testimonies to the occurrence of cholera in India during the 16 th and 17 th centuries. Lastly, there is no doubt it was recognised in the Madras Medical Board's reports previous to 1817 . The fact is, our knowledge of the diffusion of cholera in India in earlier times is imperfect and limited, as our knowledge of the country was then im. perfect and limited; but that it did prevail previous to 1817 appears indisputable, although perhaps called by other names. For instance, the word modesh, derived from modua, to tear, was adopted by the Portuguese, corrupted into mort de chien, and often applied indiscriminately to the different forms of cholera.

It is true that some of the writings on which reliance is placed both in Europe and India, to prove the antiquity of the disease, do not always describe the malady marked by suppression of urine, rice-water stools, and collapse, which in the present day is held to be true cholera. But this is only in accordance with the very numerous variations of themalady, as is sufficiently demonstrated by the number of names under which it has been described even in modern times, each term originating in some peculiar phase of the epidemic recorded. Thus we have in the writings of European authors the termsCholera Asiatica, asphyxia, algide, bilious, black, blue, dry, epidemic, endemic, febris, remittents, choleroidea, choléra foudroyante, malarious, malignant, nervous, nostras, pestiferous, hæmorrhagica, serous, simplex, spasmodic, sporadic, syncopal, and tetanic. There is also cholerine, choleriform choleroid disease, choleroid fever or sweating sickness, and the choleroid cholic of the Himalayas, which Webb regarded as a connecting link between cholera and colic. There is also reason to believe that cholera has been described as " white dysentery" and as fievre pernicieuse. Now all these are comparatively recent terms called into use by the varying nature of the malady. The disease appeared under different phases, and both in India and in Europe was described as it appeared, and therefore under a different appellation. There is indeed no disease in which the symptoms, although retaining certain characteristics, vary more. This variability of the affection was noticed on the first reputed invasion of cholera into Europe in 1832 , when Dr. Pennick ${ }^{6}$ pointed out how the epidemic in England differed from the disease in Russia. Allen Webb asked, in India, about

6 Essay on Cholera, 1832. 